Louisiana State University

LSU Digital Commons

Faculty Publications

Department of Textiles, Apparel Design \&

Merchandising

2021

\title{
Clothing Consumption During The Covid-19 Pandemic: Evidence From Mining Tweets
}

\author{
C A. Liu \\ Louisiana State University at Baton Rouge, clliu@lsu.edu
}

S B. Xia

Louisiana State University at Baton Rouge

C M. Lang

Louisiana State University at Baton Rouge

Follow this and additional works at: https://digitalcommons.Isu.edu/textile_pubs

\section{Recommended Citation}

Liu, C. A., Xia, S. B., \& Lang, C. M. (2021). Clothing Consumption During The Covid-19 Pandemic: Evidence From Mining Tweets. Clothing And Textiles Research Journal https://doi.org/10.1177/ $0887302 \times 211014973$

This Article is brought to you for free and open access by the Department of Textiles, Apparel Design \& Merchandising at LSU Digital Commons. It has been accepted for inclusion in Faculty Publications by an authorized administrator of LSU Digital Commons. For more information, please contact ir@lsu.edu. 


\title{
Clothing Consumption During the COVID-I 9 Pandemic: Evidence From Mining Tweets
}

Clothing and Textiles Research Journal 202I, Vol. 39(4) 3I4-330 (C) 202I ITAA

Article reuse guidelines: sagepub.com/journals-permissions DOI: 10.1 I77/0887302X2 I I014973 journals.sagepub.com/home/ctr @SAGE

\author{
Chuanlan Liu', Sibei Xia', and Chunmin Lang'
}

\begin{abstract}
Understanding how consumers have shifted in clothing consumption in the midst of the global COVID- 19 pandemic is critical for fashion clothing brands and businesses to identify what value means to consumers to locate growth opportunities. This exploratory study intends to provide a picture of consumers' clothing consumption evolution while going through the pandemic crisis. We take a viewpoint that integrates the perspectives of life status changes and stress coping to examine consumers' responses to clothing consumption during the COVID-19 global pandemic. A total of 68,5II relevant tweets were collected from January I, 2020, through September 3I, 2020. Sentiment and content analysis identified five themes which are revealed by 16 topics associated with clothing consumption over the phases of pre-lockdown, lockdown, and reopening. Pent-up demand for clothing products and changed clothing consumption habits were identified. Our findings provide evidence that consumption change is the fundamental mechanism of stress coping.
\end{abstract}

\section{Keywords}

COVID-I9 pandemic, consumer coping, tweet mining, clothing, consumption, consumption adjustment

The global COVID-19 pandemic and the resulting economic recession have created devastating challenges for the fashion clothing industry. The pandemic lockdown and social distancing mandates have deeply disrupted consumers' daily lives and normal consumption. Consumers radically have shifted their demand for certain essential product categories and significantly have reduced their spending on nonessentials and discretionary purchases (Arora et al., 2020; Knowles et al., 2020). Clothing buying remains a largely discretionary purchase, making it more susceptible to economic shocks caused by the pandemic. According to Census Bureau data released in mid-April 2020, clothing sales dropped by $50.5 \%$ (Callahan, 2020). Moreover, the COVID-19 pandemic has devastated the fashion industry's economic profit, which is forecasted to drop by $93 \%$ in 2020 (McKinsey, 2020). As such, the pandemic has been particularly tough on the fashion and clothing industry.

\footnotetext{
' Department of Textiles, Apparel Design and Merchandising, Louisiana State University, Baton Rouge, LA, USA

Corresponding Author:

Chuanlan Liu, Department of Textiles, Apparel Design and Merchandising, Louisiana State University, I45 Human Ecology Building, Tower and South Campus Drive, Baton Rouge, LA 708I0, USA.

Email: clliu@Isu.edu
} 
However, the pandemic crisis might also create opportunities for brands and businesses since it has produced rapid, sustained shifts in environments, markets, and consumers' needs and wants (Knowles et al., 2020). Consumption is habitual (Sheth, 2020). Once a routine in buying preference for a certain store or a particular brand is established, it becomes habitual and is difficult to change. In normal times, gaining consumers' attention and changing their preferences is a costly endeavor. However, when consumers go through daily life disruptions, they are more likely to change their consumption needs, wants, attitudes, and behavior, which leads them to be more open to new lifestyles and changes in consumption patterns and susceptible to intervention by marketers (Andreasen, 1984; Moschis, 2007). The global COVID-19 pandemic presents a timely opportunity to study consumer changes in lifestyle and consumption patterns, especially in clothing-specific lifestyle and consumptions, which could be utilitarianly and/or experientially oriented. Consumers might have practiced improvisations, and developed new spending patterns and consumption habits in clothing consumption (i.e., buying, having, using, and disposing of clothing products or related services) while going through the extended lockdown and slow reopening (Kirk \& Rifkin, 2020; Sheth, 2020). More specifically, it is not clear if disrupted clothing consumption simply turns into pent-up demand or any new consumption habits. It is critical to find out how consumers have changed their clothing consumption patterns or habits during the pandemic. This will help identify what product and service value consumers are pursuing as they establish new clothing consumption routines. It will also help marketers to navigate the crisis and locate growth opportunities by better satisfying consumers' changing needs, wants, and lifestyles.

With restrictions on movement and stay-at-home orders in place due to the COVID-19 pandemic, social media platforms have become an outlet for users to express their concerns, feelings, and opinions about the pandemic, as well as to share their new consumption practices (Depoux et al., 2020). Meanwhile, the COVID-19 outbreak has driven a growing set of research that makes use of social media data to examine public perceptions, thoughts, and concerns about the pandemic (Brough \& Martin, 2021; Nabity-Grover et al., 2020; Naeem, 2021). As the method most frequently applied to social media data, sentiment analysis employs subjectivity classification to group sentences into subjective or objective classes. Subjective sentences can express many types of information such as opinions, appraisals, emotions, beliefs, judgments, and stances (Liu, 2012). However, to our knowledge, no research has made use of social media information to understand consumers' opinions, responses, or preferences toward clothing consumption during the COVID-19 pandemic.

To this end, this exploratory study intends to provide a picture of consumers' responses or changes in clothing consumption during the global COVID-19 pandemic through mining-related tweets posted between January and September of 2020. Extensive research shows that stress is present in unexpected life events and life status changes, which trigger individuals to adjust their usual behavior patterns (Moschis, 2007). Therefore, the current study takes a viewpoint that integrates the perspectives of life status changes (Andreasen, 1984) and stress coping (Lazarus \& Folkman, 1987) to examine consumers' responses to clothing consumption during the COVID-19 global pandemic. The next section provides a literature review and research questions followed by the methodology. We then provide findings and implications for consumers, fashion and retail businesses, and practitioners. Lastly, further research is discussed.

\section{Literature Review and Research Questions}

\section{Theoretical Perspectives}

Andreasen (1984) first introduced the concepts of consumer inertia and readiness-to-change to the field of consumer behavior and marketing. He posited a working hypothesis, 
probability that a given consuming unit will change its attitudes, perceptions, and/or behavior with or without the intervention of a change agent (such as a marketer) is directly proportional to the amount and type of status change the unit has recently undergone (or is currently undergoing). (p. 784)

Based on this working hypothesis, Andreasen (1984) proposed and empirically tested the Model of Life Change Effects, which links consumer life status changes to changes in brand preferences and overall satisfaction with product and service purchases. He also identified stress and lifestyle as the intervening variables between life status change and consumption patterns changes. His research findings imply that individuals experiencing life status change are more likely to be open to marketers' interventions in the future. Andreasen (1984) identified life status change, which causes the break with the past to some extent, as a key predictor of changes in consumption patterns and behavior.

Despite merit, Andreasen (1984) narrowly conceptualized consumer changes resulting from life status changes as brand preference and purchase satisfaction changes. His model shows a lack of underlining mechanism(s), through which changes in lifestyle and consumer preferences happen (Mathur et al., 2008). Changing life status in the form of life events or life transitions creates physical, social, and emotional demands and circumstances to which individuals must adapt. Therefore, consumer scholars (e.g., Mathur et al., 2008; Moschis, 2007) posited to view consumer changes in the context of stress and coping, which provides an underlying mechanism for the links between life status changes and the resulted consumer changes in needs, wants, preferences, lifestyles, and consumption patterns.

Stress, an inevitable aspect of life, has been broadly defined as "any environmental, social, or internal demands which require the individual to readjust his/her usual behavior patterns" (Thoits, 1995 , p. 54). These demands are caused by circumstances that disrupt more or less balanced or homeostatic states that individuals previously had (Lazarus \& Folkman, 1984; Thoits, 1995). The stress perspective views changes as outcomes of a person's response to stress, which threatens the previously balanced states, by modifying or adjusting their usual action patterns to establish a new balance (Moschis, 2007). Therefore, change is the fundamental mechanism of stress coping. Lazarus and Folkman (1987) posited the Transactional Theory of Emotions and Coping (TTEC), which views stress coping as a dynamic process of changing thoughts and acts that an individual employs to manage the external and/or internal demands for a specific person-environment transaction. Consequently, the coping process concerns negative person-environment relationships due to stress and positive person-environment relationships due to getting over challenges. An individual first employs the primary appraisal to evaluate what is at stake, then employs the secondary appraisal to figure out what can be done to deal with the situation before he or she executes any coping responses when facing a particularly stressful encounter. The short-run and long-run outcomes of coping are not only manifested in behaviors such as changes in consumption patterns but also in emotional responses, mental health, and subjective well-being.

Various studies have investigated how consumers change their consumption patterns and behaviors when going through expected life events and transitions (Koschate-Fischer et al., 2018; Lee et al., 2001; Mathur et al., 2003), and unexpected life events such as natural disasters and social crises (Liu \& Black, 2011; Liu et al., 2012). For instance, Sneath et al. (2009) studied how Hurricane Katrina affected consumers. Their study found that the disaster-induced stress led consumers to impulsive and compulsive buying behaviors as coping responses to manage their emotional states, recoup losses, and restore their sense of self. When facing financial stress caused by economic challenges or a lack of resources, consumers cope with hardship by changing their established purchasing patterns to reserve resources. For instance, studies (e.g., Lee et al., 2001; Mathur et al., 2008) have found that consumers tend to be less wasteful by weighing and discussing their purchase decisions more often with their spouses, becoming more knowledgeable about various 
products and brands, and judging products and services more wisely. According to Ang et al. (2000), the consumption of non-essential goods will be highly influenced by hardship caused by resource constrains. Even though consumption of necessities is less affected, consumers tend to switch from known brands to generic brands and turn toward buying in bulk for cost savings.

Furthermore, the TTEC views coping as the process with an iterative nature (Lazarus \& Folkman, 1987); namely, coping is an ongoing process, during which responses affecting successive emotions, cognitions, and actions, in turn, affect consequent coping and so forth (Hamilton \& Catterall, 2008). Therefore, a protracted-time of disrupted daily life provides a setting in which changes over time can be assessed, and it also allows time for lasting changes in consumer behavior to emerge (Lazarus \& Folkman, 1987; Pavia \& Mason, 2004).

\section{Research Questions}

Since the COVID-19 pandemic began early in 2020, it has seen fluctuations in cases with a surge in the summer and a large surge in the fall. It is still unclear what the future will hold, leaving a period of sustained uncertainty after the global COVID-19 pandemic outbreak. Recent research has identified many new patterns in consumer shopping behavior in the midst of the pandemic, including panic buying, hoarding, rejecting (e.g., in-store shopping), changing discretionary spending (e.g., Kirk \& Rifkin, 2020; Loxton et al., 2020; Naeem, 2021), and shifts in consumer mindset and attitudes such as a focus on function, loss of interest in status-driven purchases, and interest in how the companies behind the brands are treating their employees (Knowles et al., 2020). However, this research mainly focuses on broad shifts in consumer reactions to the pandemic during the lockdown phase. Yet, little is known about consumers' specific shifts in clothing consumption as well as their shifting mindset during the extended lockdown phase of living and working from home, and the phase of gradual reopening. Moreover, extant studies on consumer behavior during the COVID-19 pandemic mainly focus on essential and utilitarian consumption, and very little is known about the role of experiential and discretionary consumption (e.g., clothing consumption) in the process of consumer changes and transitions. The individual's consumption is driven by a desire to feel good, physically and emotionally. Fashion clothing consumption is the primary part of consumers' experiential consumption, which satisfies not only individuals' desire for looking good, but also higher-level needs of love and belonging, esteem, and self-actualization. In some cases, clothing consumption reflects people's mental health and well-being when facing stressful encounters (Pavia \& Mason, 2004). The COVID-19 pandemic has significantly disrupted consumers' fashion clothing consumption. All consumption is anchored to time and location (Sheth, 2020), especially for clothing consumption. Occasions that require different dresses to allow consumers to show their different selves no longer exist during the lockdown. Stores that allow consumers to search, try on, and purchase clothing were shut down. Consumers have to make adjustments or changes in their clothing consumption, and such transitions and changes may be a part of their coping mechanism. Also, as consumers establish new consumption patterns and preferences, they may interpret and value consumption differently from before. Fashion clothing brands and businesses must identify what product and service value consumers are pursuing to be more competitive.

Based on the reviewed theoretical perspectives, we consider any changes or adjustments in clothing consumption as the fundamental mechanism of stress coping. Consequently, we view consumers' changes in clothing consumption patterns and behavior as well as shifts in their mindset as a dynamic process that the consumer employs to cope with the disrupted "clothing consumption equilibrium." Thus, we focus on exploring the following research questions: During the global COVID-19 pandemic, (1) how do consumers feel about clothing consumption? (2) is there anything perceived at stake regarding clothing consumption by consumers; is there a disruption happening in clothing consumption? (3) what changes (i.e., thoughts and acts) regarding 
clothing consumption have consumers made? (4) how do consumers' changes evolve across the different phases (i.e., pre-lockdown, lockdown, reopening) of the COVID-19 pandemic?

\section{Method}

The methodology contains three phases, data collection (Phase 1), data preprocessing (Phase 2), and data analysis (Phase 3). The phase of data collection aimed at downloading tweets representing consumer clothing behavioral changes during the pandemic. The phase of data preprocessing was aimed at cleaning and quantifying tweets data to be analyzable by machine learning algorithms. The phase of data analysis was aimed at exploring changes and potential time-series patterns within the processed data (see Figure 1).

\section{Phase I: Data Collection}

Twitter was used as the data source for this research, mainly for two reasons. Frist, Twitter, a social media platform, has become an outlet for users/consumers to express their options and feelings, especially during the pandemic. Second, Twitter offers an application programming interface (API) to access its database (Twitter Inc., 2020). El-Gayar et al. (2019) used Twitter data to study the acceptance and consumer feedback on the use of wearable devices. To collect relevant tweets, snscrape API (JustAnotherArchivist, 2020) was used to get HTML links of tweets that fell within the search criteria, and then tweepy API (Roesslein, 2020) was used to download tweets using the HTML links.

Search keywords play an important role in tweet collecting. A few sample searches were conducted to find the most appropriate combination of keywords. The researchers reviewed the collected sample tweets and finalized the search key words to be "(apparel OR clothing OR clothes) AND (COVID-19 OR corona OR pandemic)." We decided not to include the word "fashion" into the keywords for searching and collecting tweets because it was linked to too many unrelated tweets. For example, in the tweet "... our patients are not receiving them in a timely fashion. These are elderly people in the highest risk category for COVID 19 ..," both "fashion" and "COVID" were mentioned in the tweet, but the tweet has nothing to do with consumer clothing consumption. The search period was set to be from January 1, 2020, through September 30, 2020, to cover various pandemic stages (pre-pandemic, lockdown, reopening, and post-reopening). We set the langue criteria to English to avoid any need for translation. A total of 68,511 tweets were collected for this empirical study.

\section{Phase 2: Data Processing}

The cleaning processes included deletion steps (remove all the URLs, hashtags, emojis, stopwords, and punctuations) and transformation steps (lowercase transformation and lemmatization by transforming all words to their base format). The cleaned data were then converted into a matrix of word counts, referred to as tokenization. However, not all words or all tweets are at the same importance level. Therefore, the last step of preprocessing is to apply weights to words and tweets. Tweets that received an abundance of likes generate stronger influence. To apply weights on tweets, we replicated tweets based on the "like" counts. Every tweet was recounted based on its liked counts for the analysis purpose. A sample replication is shown in Figure 1 (see Step 4). The recounted number of tweets with the weighting replications was 755,774. The Term Frequency-inverse Document Frequency Transformation (tf-idf; scikit-learn developers, 2020b), one of the most popular termweighting schemes, was then applied to transform the word counts matrix to scale down the impact of words that occur very frequently but is less informative than words that occur in a small fraction 


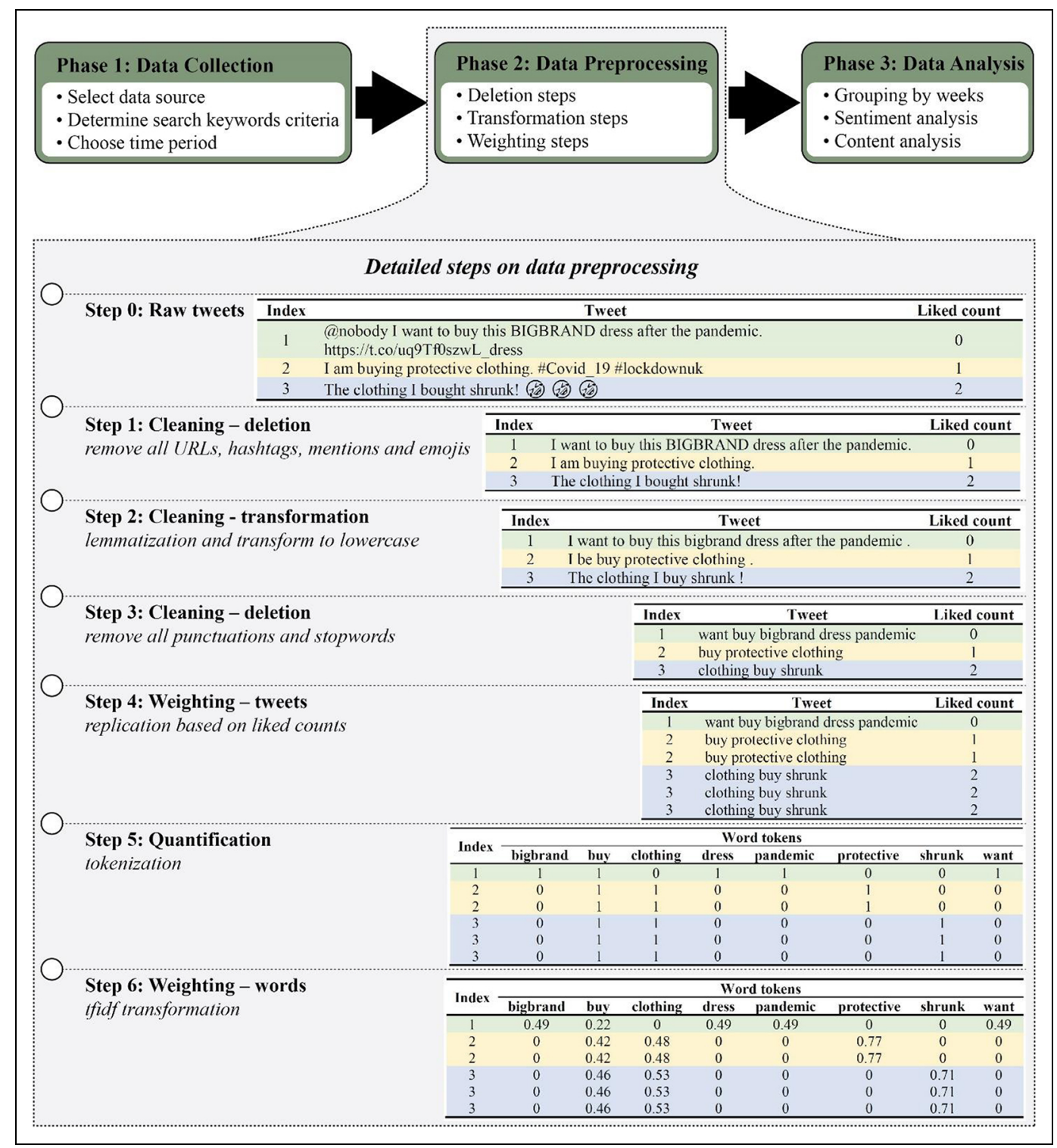

Figure I. Flowchart of data collection, preprocessing, and analysis with examples.

of the tweets (Beel et al., 2016). The nltk and sklearn APIs were used to implement these steps (NLTK Project, 2020; Pedregosa et al., 2011). Figure 1 lists all the preprocessing steps with three mock tweets as examples.

\section{Phase 3: Data Analysis}

To study the change of clothing behavior, the database was grouped by weeks. Forty units were generated, with each unit having data collected from one specific week. Sentiment and content analysis were conducted on each unit data, respectively. Sentiment analysis is the interpretation and 
classification of emotions (positive, negative, and neutral) of the text contents (Bell et al., 2018). The Textblob API (Loria, 2020) was used to calculate each tweet's sentiment score with the range of $[-1.0,1.0]$. The principle of such sentiment analysis is that Textblob has a predefined library of words and phrases assigned with polarity scores (the scores are based on other databases and training processes). When analyzing a new tweet, the program searches for each word from the tweets and returns a polarity score if the word existed in the library. The program then averages all found scores to generate an overall polarity score for the tweet. Figure 2 presents the sentiment analysis results, which include (1) the counts of negative, natural, and positive tweets (blue bars), (2) the average polarity score (yellow marks), and (3) the smoothed polarity score with a two-week moving average (yellow line) to show the polarity trend better. Moving average is a common type of smoothing technique used in time series analysis and time series forecasting (Brownlee, 2016).

Topics analysis was then applied to the 40 weekly unit data, respectively, using the NonNegative Matrix Factorization (NMF) method implemented in the sklearn API (scikit-learn developers, 2020a). The NMF method was used to extract topics from tweets from each week. Three researchers then reviewed all topics and summarized topics related to consumer clothing behavior. Sixteen topics related to clothing consumption were extracted and then grouped into five themes guided by reviewed theoretical perspectives and related literature using content analysis (Vaismoradi et al., 2013). For each of the extracted topics, representative topic words that are only directly related to the topic and not shared by other topics were picked. The word's weekly frequency (with 2-week moving average smoothing) was plotted to further explore the topic's time-series patterns (see Figure 3).

The time series patterns for the identified five themes were able to be generated by combining word frequencies of key words that fall into the same theme. For example, the topic "adapting to new clothing style" and "digitization" fall into the theme "consumption change." Therefore, the timeseries pattern of the theme "consumption change" was drawn by combing the word frequency of "embrace," "style," "adapt," "digital," and "virtual." Figure 4 presents the summary of identified topics and themes along with a time series change pattern for each identified theme.

\section{Findings and Discussions}

Results are organized mainly according to the research questions. We first describe and discuss the sentiment analysis with an intent to provide a picture of consumers' attitudes across different phases of the COVID-19 pandemic (see Figure 2). Sentiment analysis results provide answers to the first research question. We then describe and discuss results and findings from tweets mining and content analysis to provide answers to the 2 nd and 3rd research questions. Lastly, we move to discuss changes over time with an intent to answer the last research question. These findings are summarized in Figures 3 and 4.

\section{Sentiment Analysis Results}

The sentiment analysis (see Figure 2) reveals consumers' subjective overviews of opinions, appraisals, emotions, beliefs, and judgments regarding clothing consumption during the pandemic. There are not many weighted tweets related to clothing posted before the COVID-19 pandemic outbreak was officially announced. Starting from week10, two weeks before the lockdown was enforced, weighted tweets' counts suddenly increased. During the lockdown phase, weighted tweets' counts stay at high levels between 26,000 to 40,000 and reach a high point of around 45,000 in Week 21 when states started reopening. Then the counts of weighted tweets rise and fall between 11,000 and 35,000 after reopening. These changes in weighted tweet counts provide evidence that the pandemic 




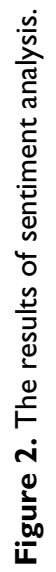




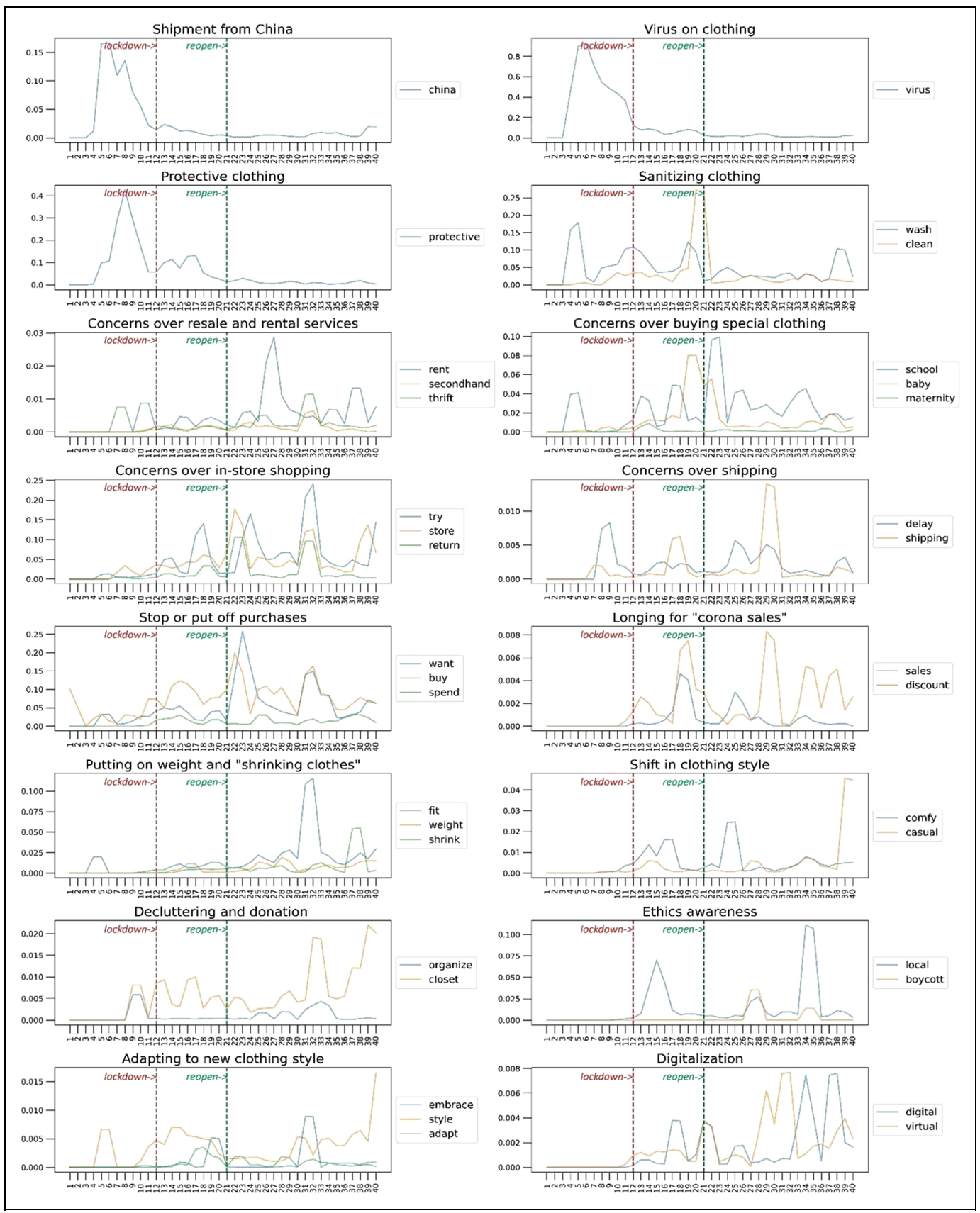

Figure 3. Identified topics and trends related to clothing consumption during the COVID-19 pandemic.

created stress to consumers and disruption to their clothing consumption, which activate consumers' coping process.

Polarity analysis results show that the overall tweet tone stays slightly positive with some degree of fluctuation during the lockdown time, indicating that consumers, even with some degree of concerns, might have accepted lockdown as an effective way to defend against perceived safety 




Figure 4. Summary of identified topics, themes, and trends related to clothing consumption during the COVID-19 pandemic.

threats. The positive attitude reached the highest around the first few weeks of reopening, then dropped with some degree of up-and-down fluctuation afterward, indicating that consumers were highly positive about clothing consumption right after reopening, but became less positive afterward because of the unexpected pandemic protraction.

To be noted here, the weighted tweets peaked in week 30 with a significant increase in negative tweet count. By looking into tweets' details, we found that one tweet with a negative tone was liked more than $60 \mathrm{k}$ times. Because we weighted all tweets based on their liked times, this tweet skewed the total number of negative tweet counts in that week. Interestingly, we found that the tweet complained about people using the extra unemployment money on buying clothing while such money was not available for employed workers. This finding indirectly provides evidence that consumers do share their opinions, thoughts related to clothing consumption, and behavior through social media. Also, buying clothing is not considered rational when people have limited resources. Overall, consumers feel slightly positive about clothing consumption, and their attitudes rise and fall consistently with the status of the pandemic over time.

\section{Tweets Mining and Content Analysis Results}

To find out how consumers appraise the unexpected life event of the COVID-19 pandemic, we conducted tweets mining and content ANALYSIS. We identified 16 topics: shipment from China, virus on clothing, protective clothing, sanitizing clothing, concerns over resale and rental services, concerns over in-store shopping, concerns over shipping, stop or put off purchases, longing for 
"corona sales," putting on weight and "shrinking clothes," shift in clothing style, decluttering and donation, ethics awareness, adapting to new clothing style, and digitalization (see Figure 3). Based on the reviewed theoretical perspectives and related literature, we consider any changes or adjustments in clothing consumption as the fundamental mechanism of stress and disruption. Also, we view consumers' changes in clothing consumption as a dynamic process of changing thoughts and actions that the consumer employs to cope with the disrupted "clothing consumption equilibrium." We grouped the 16 topics into five themes: safety concern, consumption disruption, pent-up demand, consumption transition, and consumption changes. Consumers perceive safety is at risk, and they also experience or anticipate disruptions in their clothing consumption. The results not only provide evidence that consumers put off or stop spending on clothing, but also indicate consumers went through clothing consumption transitions and adapted to the environment with changes in clothing consumption. Figure 4 summarizes identified consumer responses and actions regarding clothing consumption during the COVID-19 pandemic.

Safety concerns. The extracted topics, including shipment from China, virus on clothing, protective clothing, and sanitizing clothing, provide evidence that consumers worried about bringing the virus directly or indirectly through clothing. For instance, some tweets indicate, "It's impossible for a shop to be protected from corona, even a non-infected could be carrying the virus on their clothes and inadvertently spread it if they touch the virus and touch surfaces..." Also, consumers showed concern over the clothing products ordered online, especially those shipped from China. As Figure 3 presents, those words such as "China," "virus," "protective," "wash," and "clean" were frequently mentioned when the pandemic just started. As tweets described, "our clothes are made in china and china has the coronavirus so would they just stop shipping clothes?" "I ordered clothes from China and I am scared. Can the coronavirus carry on the clothing?!" In addition, sanitizing clothes became a daily habit. Like some tweets described, "With coronavirus going around, I better not see ANYBODY laying in bed with their outside clothes!" "All clothing removed and wear "house clothes," shoes off and wear slippers." "Coronavirus paranoia has me in overdrive, thoroughly wiping everything. Every piece of clothing I wear gets washed every week or two. Towels and bedsheets as well; can't be too careful."

For the sake of safety, people care for protective clothing. Hygiene products such as masks, face shields, and protective clothing were considered necessities. To defend against perceived safety threats, consumers started searching for protective clothing and items. For instance, people started posting more tweets about looking for protective clothing, "I would buy protective clothing for Coronavirus," and "We are looking for protective clothing for coronavirus, does anyone know of any agents?"

Consumption disruption. The identified topics of concerns over in-store shopping, concerns over resale and rental services, and concerns over shipping not only provide evidence that consumers experienced disruption in clothing consumption but also illustrate what specific disruptions made consumers worried. Worrying that the virus on the clothes would be inadvertently spread disrupted people from purchasing clothing products, like a tweet stated, "Can you imagine trying on clothes during a pandemic transferring the virus to everyone who touches or breathes on the garments." With the outbreak of the pandemic, the concerns over in-store shopping increased among consumers. Consumers simply cut down spending on fashion clothing and started recycling whatever was in the wardrobe to avoid going to stores and trying on clothes. Like some tweets described, "Shopping practices will have to change in the post-pandemic world." Some people also stopped purchasing clothing because they could not try on clothes and worried that they could not return if it did not fit, "So you can't try on clothes at stores, and they won't let you return clothes that won't fit?" Even though online shopping has made it possible for consumers to purchase fashion products, both 
domestically and internationally, the rapid spread of COVID-19 and the high levels of uncertainty made it hard for consumers to enjoy online purchases. For instance, some tweets stated, "All factories are forced on vacation due to the Corona Virus thing, and the samples are delayed, so the links for ordering are being delayed too;" and "This Corona Virus needs to stop cause I want to buy some really cute clothes online, but they have to come from China so they "aren't available."

Pent-up demand. The emerged topics of stopped or put off purchases, longing for "corona sales" provide evidence that consumers' desire for clothing consumption still exists, and it is temporary for them to stop spending on clothing. For example, some tweets described, "If clothing companies could stop having online deals that would be great, I'm trying to save money during the pandemic!;" "I need new clothes BUT thanks to COVID I can't go out shopping and can't order online." Also, we found evidence of pent-up demand due to disruption. For instance, one tweet stated, “. . . this corona pandemic isn't going away any time soon so stop spending all your money ordering "summer clothes." Moreover, the emerged topic of putting on weight and "shrinking clothes" make it reasonable to assume there will be a pent-up clothing demand as consumers are sizing up after their prolonged stay at home. Like some tweets stated, "None of my clothes are going to fit by the time this pandemic is over;" "Pandemic side effect: my clothes are shrinking." "I've literally cried these past few days because the only things that fit me now are oversized sweaters and my husband's gym shorts. I have to wait until after the pandemic to try on clothes that fit...."

Consumption transition. Consumption transition is manifested by four identified topics: shift in clothing style, putting on weight and "shrinking clothes," decluttering and donation, and ethics awareness. During the lockdown period, many people work from home and reduce the frequency of going out. Dressing for zoom calls and going nowhere meant that the same lounge pants, jeans, and a few smart tops became people's new capsule wardrobe. For instance, some people tweeted, "Currently packing up my work clothes for storage. Pandemic life is just life now. Only soft pants live in my closet now." In addition, staying at home and working from home may have changed people's eating or exercise habits. It is common for people to gain weight and have clothing fit issues. The COVID-19 pandemic has taught people that less can be more. During the lockdown, consumers use their time to clear their wardrobe and set aside their unwanted clothing for the charity shop. For instance, some people tweeted, "Wash your clothes and deep clean your whole house, reorganize everything and declutter, throw out stuff that's no longer needed or save it for after the pandemic and donate it to a local shelter or Salvation Army!" In addition, instead of scouring for new clothes to buy, people dig deep in their existing wardrobe and find buried clothing items that they have not worn for a while. Also, shifts in consumers' mindset and attitudes were observed. For instance, the concerns about the development of the country, the community, and the local business are increasing, as some tweets described, "When the Corona Virus finally exhausts itself and the danger is over, let's Promise and do something good for our country;" "Support local businesses during the pandemic however you can!"

Consumption change. Two major consumption changes were identified after entering the lockdown period. The first major consumption change is about clothing style. Word counts for "embrace," "style," and "adapt" rise and fall with an overall increasing pattern after the lockdown, providing evidence to the identified change in clothing consumption. Tweet content analysis finds that comfort becomes a more favored style since the outbreak of the pandemic. As many people start working from home, they prefer comfortable and casual styles. Like some tweets indicated, "Since this pandemic started, when I'm at home I wear the most comfy, mismatched clothes." Tweet mining results indicate comfortable work-from-home clothes were favored over other clothing styles during the peak of the lockdown period (March-April). Gradually, wearing staying-home style and 
recycling existing wardrobe have become a clothing consumption habit. One tweet indicated, "I've been basically living in loungewear onesies during the pandemic. I don't think I can ever go back to wearing real clothes again."

The other identified change is digitization. Tweet mining results showed that words of "digital" and "virtual" frequently appeared in the posted tweets after the lockdown. Figure 3 also shows that the counts for these two words increase significantly after reopening. With more consumers shopping online, virtual and digital fashion attract consumers' attention. Tweet content analysis further provides the evidence. For instance, some tweets described, "With fashion weeks going digital because of COVID-19, 3D artists are being hired to create virtual clothes and even models"; "This is the visual representation of clothing created using 3D design technology. For example, Hanifa showcased their new collection." Digital fashion and digital contactless clothing trying-on technology might be another significant change in clothing consumption in a post-pandemic world.

\section{Changes Over Time}

During the pre-lockdown period, safety was identified as the major concern for consumers, which rose sharply when the pandemic first started and peaked on week 5 (January 27-February 2). However, consumption disruption, pent-up demand, consumption transition, and consumption change followed a similar pattern at the beginning of the pandemic during week 1 to week 12 , which gradually penetrated consumers' lives, but was not distinct. When it came to the lockdown period, the level of safety concerns quickly dropped. Instead, consumers started being influenced by the disruption, especially for clothing categories such as maternity and children's wear. The trend of consumption disruption and pent-up demand followed a similar pattern, which increased slowly before the reopening. However, it was interesting to see the slight drop in the trends during the lockdown period (Week 15, April 6-12). This might be because the lockdown bent the curve of the case number, and some consumers started to purchase clothing items. The frequency of some topic representative words such as "sell," "sales," "discount," "local," and "comfy," which have a low frequency at the early stage of the pandemic gradually increased during the lockdown period, indicating consumers gradually transitioned to the new living environment and started purchasing clothing with reduced panic and concerns.

During the reopening period, safety concerns on clothing were no longer the major issue. This could be because consumers got used to cleaning and sanitizing clothing products. However, the changes of the other four trends started getting more distinct. Consumption disruption and pent-up demand followed a similar pattern in this stage. With the reopening and growing number of cases, concerns over consumption disruption increased sharply. Meanwhile, the pent-up demand trend increased again and got more distinct, possibly due to the increased need for clothing. After reopening (Week 25, June 15-21), more consumption transitions and changes happened when consumers started to adapt to the new working style, with some of them gaining weight and no longer fitting into their old clothing. The frequency of some topic representative words, such as "digital," "virtual," and "embrace," which have a low frequency at the early stages, increased steadily in the reopening period.

\section{Conclusion, Implications, and Limitations}

The lockdown and social distancing to combat the COVID-19 pandemic have generated significant disruptions in clothing behavior. Through mining and analyzing collected tweets related to clothing consumption, we answered the research questions. Specifically, sentiment analysis reveals that consumers' overall attitude toward clothing consumption in the midst of the pandemic is slightly positive with up and down fluctuations, indicating the consumers are able to manage the stress or 
disruption caused by the global pandemic. Findings through tweets mining and content analysis showed that consumers perceived their safety was at stake, and the virus could be spread directly or indirectly through clothing from their primary appraisal. They also experienced or foreknew consumption disruption. Facing consumption disruption, consumers rationally responded with pent-up demand as a short-run coping outcome. To cope with consumption disruption, consumers also improvised with different consumption adjustments to make consumption transitions, and eventually adapt to the new environment and situation with consumption change, including the shift in clothing styles to favor comfort more, decluttering to switch to simplism and shopping more online. Also, we found shifts in consumer mindset and attitudes toward clothing consumption. Consumers care about how brands are treating their employees and are willing to support local businesses. Moreover, the analysis on the changing patterns of the identified themes about clothing consumption over time provides evidence to support consumer changes in clothing consumption during the COVID-19 pandemic. Namely, consumers' responses, adjustments, and changes in clothing consumption manifest the process of their coping with stress and disruption due to the pandemic.

The COVID-19 crisis has surfaced as a great research opportunity to understand consumer changes, resilience, and improvisation over time (Sheth, 2020). Our findings provide evidence that consumption change is the fundamental mechanism of stress coping. Also, clothing consumption is discretionary, and consumers cut or postpone spending on clothing to reserve resources and gain control in an uncertain time. Clothing consumption may also function as a buffer for consumers to deal with stressful external environments. For instance, consumers switching to comfort clothing styles might be due to the need to feel relaxed or less stressed. Previous research found that consumers crave products or services that provide comfort during a time of anxiety (Carver et al., 1989). Also, clothing consumption, which involves discretionary resources and individual creativity, provides a good setting to understand consumer resilience and creative consumption. Thus, future studies may find fruitful results from examining how fashion clothing consumption improvisation and adjustment are associated with consumers' coping resilience, lifestyle changes, and well-being.

There are two managerial implications of the study. First, disrupted consumption is also linked to pent-up demand. As consumers cut or postpone spending on purchasing new fashion clothing, their needs for special clothing (e.g., school uniform, baby clothes, and maternity clothing) and desire to express themselves through fashion clothing consumption are deprived. The longer consumers are deprived of fashion clothing consumption, the stronger desires they will have for fashion clothing consumption. Once they do not have concerns over shopping, shipping, and virus on clothing, they have a desire for fashion clothing. For instance, Chinese shoppers' data during and after the lockdown reveals new trends that Chinese consumers are indulging in "revenge consumption" in the post-COVID-19 era (Yang \& Kidron, 2020). When consumers feel anxious and cut or put off spending on fashion clothing, fashion businesses should work on keeping and improving relationships with customers by providing concern-free and convenient shopping, shipping, and returning services. A second managerial implication is that the fashion business must learn to adapt business operations to meet consumers' changing needs and wants. According to Lazarus and Folkman (1987), individual coping responses and actions associated with positive attitudes or emotional reactions last longer than those associated with negative attitudes. Based on our findings, fashion clothing business might consider going back to the fundamentals and identifying new values their customers are seeking. For instance, the shift to work from home has made consumers more pragmatic in fashion clothing consumption. Consumers pay more attention to "waist-up" clothing. Also, consumers prefer comfort over style. These improvised fashion clothing consumption practices may become new habits while going through the extended intermediated phase of the pandemic. Therefore, fashion business must match their offers with consumer demands. Furthermore, more consumers are embracing online shopping channels, and the fashion business must develop its infrastructure to provide seamless online or omnichannel experiences. Overall, fashion businesses 
need to be more resilient and provide solutions to better meet consumers' changing needs, wants, and desires for clothing.

This exploratory study has limitations. We focused on examining consumers' clothing consumption changes from a stress-coping perspective; however, we were not able to assess individual or mass consumers' stress levels or the relationship between stress and changes through mining aggregated tweets. Also, we intended to focus on examining changes over time, but we were not able to conduct a longitudinal study. We only analyzed multiple cross-sectional data sets with the assumption there is a linear continuity between data sets. Moreover, people who tend to share on Twitter may not represent the general consumer population, limiting the generalizability of our findings. Lastly, we filtered the tweets based on language information instead of location information that was missing for most tweets. However, the lockdown and reopening times for different locations may vary to some extent, providing different results.

\section{Acknowledgment}

Authors would like to extend our sincere thanks to anonymous reviewers for providing helpful comments and suggestions on earlier drafts of the manuscript.

\section{Declaration of Conflicting Interests}

The author(s) declared no potential conflicts of interest with respect to the research, authorship, and/or publication of this article.

\section{Funding}

The author(s) received no financial support for the research, authorship, and/or publication of this article.

\section{References}

Andreasen, A. R. (1984). Life status changes and changes in consumer preferences and satisfaction. Journal of Consumer Research, 11(3), 784-794.

Ang, S. H., Leong, S. M., \& Kotler, P. (2000). The Asian apocalypse: Crisis marketing for consumers and businesses. Long Range Planning, 33(1), 97-119.

Arora, N., Charm, T., Grimmelt, A., Ortega, M., Robinson, K., Sexauer, C., \& Yamakawa, N. (2020). A global view of how consumer behavior is changing amid COVID-19. McKinsey and Company.

Beel, J., Gipp, B., Langer, S., \& Breitinger, C. (2016). Research-paper recommender systems: A literature survey. International Journal on Digital Libraries, 17(4), 305-338. https://doi.org/10.1007/s00799-0150156-0

Bell, E., Bryman, A., \& Harley, B. (2018). Business research methods. Oxford university press.

Brough, A. R., \& Martin, K. D. (2021). Consumer privacy during (and after) the COVID-19 pandemic. Journal of Public Policy \& Marketing, 40(1), 108-110.

Brownlee, J. (2016). Moving average smoothing for data preparation and time series forecasting in Python. $\mathrm{https}$ ://machinelearningmastery.com/moving-average-smoothing-for-time-series-forecasting-python/

Callahan, C. (2020, April). How coronavirus could alter the way we shop for clothes from now on. https://www. today.com/style/how-coronavirus-could-alter-way-we-shop-clothes-now-t180039

Carver, C. S., Scheier, M. F., \& Weintraub, J. K. (1989). Assessing coping strategies: A theoretically based approach. Journal of Personality and Social Psychology, 56(2), 267.

Depoux, A., Martin, S., Karafillakis, E., Preet, R., Wilder-Smith, A., \& Larson, H. (2020). The pandemic of social media panic travels faster than the COVID-19 outbreak. Oxford University Press.

El-Gayar, O., Nasralah, T., \& Elnoshokaty, A. (2019). Wearable devices for health and wellbeing: Design insights from twitter. In Proceedings of the 52nd Hawaii International Conference on System Sciences, Maui, Hawaii, USA, January 7-10, 2020. 
Hamilton, K., \& Catterall, M. (2008). "I can do it!" Consumer coping and poverty. ACR North American Advances, 35, 551-556.

JustAnotherArchivist. (2020). Justanotherarchivist/snscrape. https://github.com/JustAnotherArchivist/ snscrape

Kirk, C. P., \& Rifkin, L. S. (2020). I'll trade you diamonds for toilet paper: Consumer reacting, coping and adapting behaviors in the COVID-19 pandemic. Journal of Business Research, 117, 124-131.

Knowles, J., Ettenson, R., Lynch, P., \& Dollens, J. (2020). Growth opportunities for brands during the COVID-19 crisis. MIT Sloan Management Review, 61(4), 2-6.

Koschate-Fischer, N., Hoyer, W. D., Stokburger-Sauer, N. E., \& Engling, J. (2018). Do life events always lead to change in purchase? The mediating role of change in consumer innovativeness, the variety seeking tendency, and price consciousness. Journal of the Academy of Marketing Science, 46(3), $516-536$.

Lazarus, R. S., \& Folkman, S. (1984). Stress, appraisal, and coping. Springer Publishing Company.

Lazarus, R. S., \& Folkman, S. (1987). Transactional theory and research on emotions and coping. European Journal of Personality, 1(3), 141-169.

Lee, E., Moschis, G. P., \& Mathur, A. (2001). A study of life events and changes in patronage preferences. Journal of Business Research, 54(1), 25-38.

Liu, B. (2012). Sentiment analysis and opinion mining. Synthesis Lectures on Human Language Technologies, $5(1), 1-167$.

Liu, C., \& Black, W. (2011). Post-disaster consumer coping: Consumption adjustment. ACR Asia-Pacific Advances, 9, 214-221.

Liu, C., Black, W. C., Lawrence, F. C., \& Garrison, M. B. (2012). Post-disaster coping and recovery: The role of perceived changes in the retail facilities. Journal of Business Research, 65(5), 641-647.

Loria, S. (2020). TextBlob. https://github.com/sloria/TextBlob (Original work published 2013)

Loxton, M., Truskett, R., Scarf, B., Sindone, L., Baldry, G., \& Zhao, Y. (2020). Consumer behaviour during crises: Preliminary research on how coronavirus has manifested consumer panic buying, herd mentality, changing discretionary spending and the role of the media in influencing behaviour. Journal of Risk and Financial Management, 13(8), 166.

Mathur, A., Moschis, G. P., \& Lee, E. (2003). Life events and brand preference changes. Journal of Consumer Behaviour: An international Research Review, 3(2), 129-141.

Mathur, A., Moschis, G. P., \& Lee, E. (2008). A longitudinal study of the effects of life status changes on changes in consumer preferences. Journal of the Academy of Marketing Science, 36(2), 234-246.

McKinsey. (2020). The State of Fashion 2021: In search of promise in perilous times / McKinsey. https://www. mckinsey.com/ /media/McKinsey/Industries/Retail/Our\%20Insights/State\%20of\%20fashion/2021/TheState-of-Fashion-2021-vF.pdf

Moschis, G. P. (2007). Life course perspectives on consumer behavior. Journal of the Academy of Marketing Science, 35(2), 295-307.

Nabity-Grover, T., Cheung, C. M., \& Thatcher, J. B. (2020). Inside out and outside in: How the COVID-19 pandemic affects self-disclosure on social media. International Journal of Information Management, 55, 102188 .

Naeem, M. (2021). Do social media platforms develop consumer panic buying during the fear of Covid-19 pandemic. Journal of Retailing and Consumer Services, 58, 102226.

NLTK Project. (2020). Natural language toolkit—NLTK 3.5 documentation. http://www.nltk.org/index.html

Pavia, T. M., \& Mason, M. J. (2004). The reflexive relationship between consumer behavior and adaptive coping. Journal of Consumer Research, 31(2), 441-454.

Pedregosa, F., Varoquaux, G., Gramfort, A., Michel, V., Thirion, B., Grisel, O., Blondel, M., Prettenhofer, P., Weiss, R., \& Dubourg, V. (2011). Scikit-learn: Machine learning in Python. The Journal of Machine Learning research, 12, 2825-2830.

Roesslein, J. (2020). Tweepy. https://github.com/tweepy/tweepy 
scikit-learn developers. (2020a). Sklearn.Decomposition.NMF-scikit-learn 0.23.2 documentation. https://sci kit-learn.org/stable/modules/generated/sklearn.decomposition.NMF.html

scikit-learn developers. (2020b). Sklearn.Feature_extraction.Text.Tfidftransformer-scikit-learn 0.23.2 documentation. https://scikit-learn.org/stable/modules/generated/sklearn.feature_extraction.text.TfidfTransfor mer.html\#sklearn.feature_extraction.text.TfidfTransformer

Sheth, J. (2020). Impact of Covid-19 on consumer behavior: Will the old habits return or die? Journal of Business Research, 117, 280-283.

Sneath, J. Z., Lacey, R., \& Kennett-Hensel, P. A. (2009). Coping with a natural disaster: Losses, emotions, and impulsive and compulsive buying. Marketing Letters, 20(1), 45-60.

Thoits, P. A. (1995). Stress, coping, and social support processes: Where are we? What next? Journal of Health and Social Behavior, 35, 53-79.

Twitter Inc. (2020). Twitter API documentation. https://developer.twitter.com/en/docs/twitter-api

Vaismoradi, M., Turunen, H., \& Bondas, T. (2013). Content analysis and thematic analysis: Implications for conducting a qualitative descriptive study. Nursing \& Health Sciences, 15(3), 398-405.

Yang, V., \& Kidron, E. (2020). Revenge consumption-The new shopping trend that can shake up sleepy markets post-Covid. https://theprint.in/india/revenge-consumption-the-new-shopping-trend-that-can-shakeup-sleepy-markets-post-covid/481065/

\section{Author Biographies}

Chuanlan Liu, PhD and MBA, is a professor of merchandising at Louisiana State University. Her research focuses on consumer experiences, slow fashion, mass customization, and sustainability, branding, and entrepreneurship in fashion. Dr. Liu's research has been recognized nationally and internationally. She has published research in Journal of Business Research, Journal of Interactive Marketing, and International Journal of Consumer Studies, and others.

Sibei Xia, $\mathrm{PhD}$, is an assistant professor in the Department of Textiles, Apparel Design, and Merchandising at Louisiana State University. Her expertise is in customized product development, fashion technologies, and fashion data mining. Dr. Xia's research has been published in Clothing and Textile Research Journal, The Journal of The Textile Institute, Journal of Fashion Marketing and Management, and others.

Chunmin Lang, $\mathrm{PhD}$, is an assistant professor of merchandising at the department of textiles, apparel design and merchandising at Louisiana State University. Her research interests include sustainable consumption and fashion entrepreneurship. Dr. Lang's research has been published in Journal of Fashion Marketing and Management, Journal of Consumer Behavior, Journal of Cleaner Production, Sustainable Development, Journal of Consumer Policy, among others. 